\title{
BLDC Drive Control using Artificial Intelligence Technique
}

\author{
Laxmiprasanna Ch \\ PG scholar \\ Siddhartha Institute of Engineering and Technology
}

\begin{abstract}
This paper proposed a control scheme of a neural network for the brushless direct current (BLDC) permanent magnet motor drives. The behavior of BLDC motor drive is nonlinear, cause it is complex to handle by using conventional proportional-integral (PI) controller. In order to overcome this main problem, artificial neural network controller technique is developed. The controller is intended to tracks variations of speed references and stabilizes the output speed during load variations. The mathematical model of BLDC motor and artificial neural network algorithm is derived. The effectiveness of the proposed method is established by developing simulation model in MATLAB/ Simulink. The simulation results show that the proposed Artificial neural network controller construct substantial improvement of the control performance compare to the PI controller for both condition controlling speed reference variations and load disturbance variations.
\end{abstract}

\section{Keywords}

BLDC, Permanent Magnet, PI controller, ANN

\section{INTRODUCTION}

Brushless Direct Current (BLDC) motors comprise several attractive properties such as smooth speed control and torque speed characteristics [1]. Moreover, the control of DC motor also simple and does not requires complex Hardware [2, 3]. But, DC motors have main disadvantages regarding to lifetime of brushes are the limited. A lower reliability occurs caused by the brushes and the operation need time to time maintenance of replacement [4].

BLDC motors recommend a few advantages such as structure is simple and compact size, robust and highly efficient and Reliable performance [5]. BLDC motors also offer additional advantages such as greater speed capabilities and better speed versus torque characteristics. Due to the BLDC operate without brushes its lifetime spent can be increased and maintenance operation can also avoid.

The indication of previous research that the permanent magnet motor drives, which includes the permanent magnet synchronous motor (PMSM) and the brushless dc motor (BLDC) might develop into severe rival to the induction motor for industrial applications.

The BLDC Motors have developing constant electric torque by a trapezoidal back EMF, and rectangular stator currents are needed. Generally, Hysteresis or pulse width-modulated (PWM) controllers

are used to preserve the definite currents flowing into the motor and the same as possible to the rectangular reference values[6].

\section{THE ANALYSIS BLDC MOTOR DRIVE} SYSTEM

The analysis of BLDC motor is based on the assumption for simplification and windings are equal and the self and Mutual inductances are constant.

\author{
Ramesh Palakeerthi \\ Assoc Prof \& HOD \\ Siddhartha Institute of Engineering and Technology
}

The dynamic equations of BLDC motor using Assumptions can be derived as

$$
\begin{aligned}
& V_{a}=R I_{a}+(L-M) \frac{d i_{a}}{d_{t}}+e_{a} \\
& V_{b}=R I_{b}+(L-M) \frac{d i_{b}}{d_{t}}+e_{b} \\
& V_{c}=R I_{c}+(L-M) \frac{d i_{c}}{d_{t}}+e_{c}
\end{aligned}
$$

Where $\mathrm{V}_{\mathrm{a}}, \mathrm{V}_{\mathrm{b}}, \mathrm{V}_{\mathrm{c}}=$ Stator phase voltages

$$
\begin{array}{ll}
\mathrm{I}_{\mathrm{a}}, \mathrm{I}_{\mathrm{b}}, \mathrm{I}_{\mathrm{c}} & =\text { Stator phase currents } \\
\mathrm{e}_{\mathrm{a}}, \mathrm{e}_{\mathrm{b}}, \mathrm{e}_{\mathrm{c}} & =\text { Back emf of phases } \\
\mathrm{L} & =\text { Self inductance } \\
\mathrm{M} & =\text { Mutual inductance } \\
\mathrm{R} & =\text { Phase Resistance }
\end{array}
$$

The Motion equation is defined as

$$
\begin{aligned}
& \frac{d_{\omega_{m}}}{d_{t}}=\left(\frac{p}{2 j}\right)\left(T_{e}-T_{l}-B \omega_{r}\right) \\
& \frac{d_{\theta}}{d_{t}}=\omega_{r}
\end{aligned}
$$

Where $\mathrm{Te}=$ the electromagnetic torque

$$
\begin{aligned}
& \mathrm{T}_{1}=\text { Load torque } \\
& \mathrm{J} \quad=\text { Moment of inertia }\left(\mathrm{kgm}^{2}\right) \\
& \mathrm{B} \quad=\text { Friction coefficient }(\mathrm{Nm} / \mathrm{rad}) \\
& \omega_{m}=\text { Rotor speed in mechanical }(\mathrm{rad} / \mathrm{sec}) \\
& \omega_{e}=\text { Rotor speed in electrical }(\mathrm{rad} / \mathrm{sec}) \\
& \omega_{e}=\text { Rotor speed in electrical }(\mathrm{rad} / \mathrm{sec})
\end{aligned}
$$

\section{CONTROLLER DESIGN}

\subsection{PI speed control of the BLDC motor}

The PI control drive consists of speed controller, reference current generator, PWM current controller, position sensor, the motor and IGBT based current controlled voltage source inverter (CC-VSI). The motor speed is compared with its reference value and the speed error is developed in proportional- integral (PI) speed controller.

$$
e(t)=\omega_{r e f}-\omega_{m}(\mathrm{t})
$$

$\omega_{m}(t)$ is compared with reference speed $\omega_{\text {ref }}$ and resulting error is estimated at the $\mathrm{n}^{\text {th }}$ sampling instant as

$$
\mathrm{T}_{\text {ref }}(\mathrm{t})=\mathrm{T}_{\text {ref }}(\mathrm{t}-1)+\mathrm{K}_{\mathrm{P}}(\mathrm{e}(\mathrm{t})-\mathrm{e}(\mathrm{t}-1))+\mathrm{K}_{\mathrm{I}} \mathrm{e}(\mathrm{t})
$$


where $\mathrm{K}_{\mathrm{p}}$ and $\mathrm{K}_{\mathrm{I}}$ are the gains of PI controller.

The controller output is considered as the reference torque. A limit is put on the speed controller output depending on permissible maximum winding currents. The reference current generator block generates the three phase reference currents ia $i_{b}$, $i_{c}$ using the limited peak current magnitude decided by the controller and the position sensor.

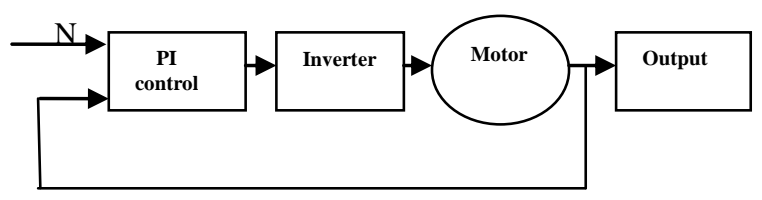

Fig .1.Block diagram of BLDC motor by PI controller

\subsection{Artificial Neural Network controller}

The structure of the proposed neural network control of a BLDC motor is shown in fig.2. Based on the number of neurons in each layer of the proposed ANN architecture

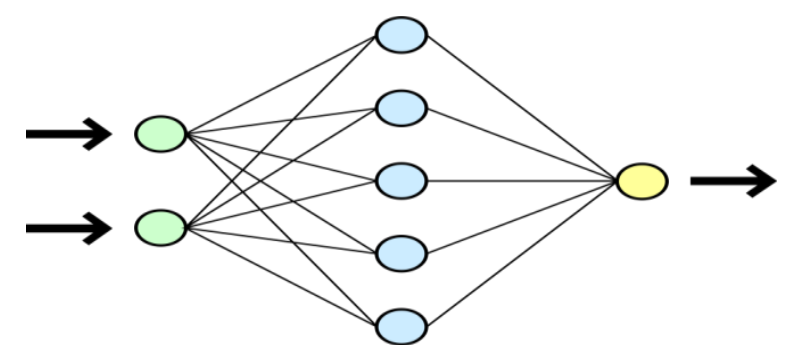

Fig .2.Architecture of the proposed ANN controller

The connections weight parameter between $j_{\text {th }}$ and $i_{\text {th }}$ neuron at $\mathrm{m}_{\mathrm{th}}$ layer is given by $\mathrm{w}_{\mathrm{ij}}$ while bias parameter of this layer at $i_{\mathrm{th}}$ neuron is given by $b_{m i}$.

Transfer function of the network at $t_{t h}$ neuron in $\mathrm{m}_{\mathrm{th}}$ layer is defined as

$n_{i}^{m}=\sum_{j=1}^{s^{m-1}} w_{i j}^{m} a_{j}^{m-1}+b_{i}^{m}$

The output function of neuron at $\mathrm{m}^{\text {th }}$ layer is given by

$a_{i}^{m}=\mathrm{f}^{\mathrm{m}}\left(\mathrm{n}_{\mathrm{i}}^{\mathrm{m}}\right)$

(10)

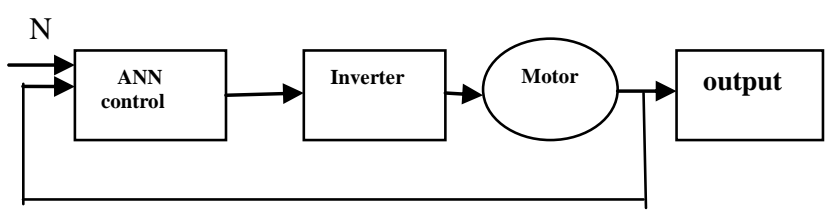

Fig. 3 Block diagram of BLDC motor by ANN controller

Table.1: Parameters of BLDC Motor used in Simulink /Matlab

\begin{tabular}{|l|l|}
\hline Parameters & Value \\
\hline Resistance $(\mathrm{Ohms})$ & $1.43 \Omega$ \\
\hline Inductance $-(\mathrm{H})$ & $9.4 \mathrm{e}^{-3}$ \\
\hline Flux-(Weber) & 0.2158 \\
\hline Friction coefficient & $2 \mathrm{e}^{-3}$ \\
\hline Poles of motor & 4 \\
\hline DC voltage source(V) & 380 \\
\hline
\end{tabular}

\begin{tabular}{|l|l|}
\hline Rotor Inertia-(J) & $1.5 \mathrm{e}^{-3}$ \\
\hline
\end{tabular}

\section{SIMULATION RESULTS}

The BLDC is running at Zero values at zero speed and NoLoad.the experimental results at different instants of time for the different command signals are shown. Fig 4 to 7 Shows the BLDC outputs for PI \& ANN controllers at time $\mathrm{t}=0 \mathrm{sec}$, when the command of speed 1000RPM, torque $3 \mathrm{~N}-\mathrm{M}$ is applied. Fig 8 to 11 shows the outputs of both controllers at time $t=0.4 \mathrm{sec}$, the speed command increases from 1000RPM to 2000RPM. Fig 12 to 15 shows the outputs at $\mathrm{t}=0.7 \mathrm{sec}$ and the speed decreases from 2000RPM to 500RPM.Fig 16 to 19 shows the outputs at $t=1.2 \mathrm{sec}$ when the load increases from $3 \mathrm{Nm}$ to $7 \mathrm{Nm}$.From all the results we can observe that the ANN control is giving the better results than the PI controller, the proposed controller is controlling the speed, torque, current and Back EMF with in a very short span of time with accurate outputs.
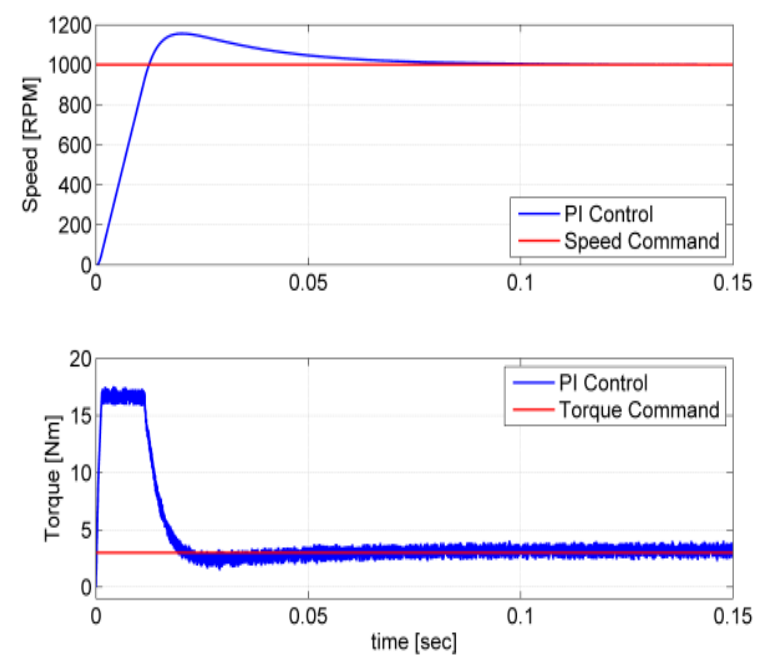

Fig.4. Figure shows the speed and torque response of PI controller at $\mathbf{t}=0 \mathrm{sec}$, here by $\mathrm{PI}$ controller the speed is controlled at $\mathrm{t}=\mathbf{0 . 0 7} \mathrm{sec} \&$ the torque is controlled at $\mathrm{t}=\mathbf{0 . 0 2}$ sec.
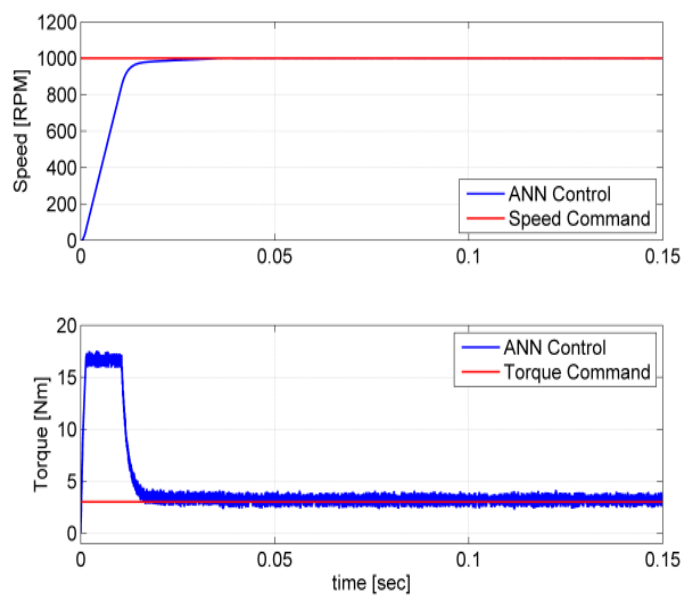

Fig5. Figure shows the Speed and torque response of ANN controller from $t=0$ sec. here by ANN controller the speed is controlled very quickly that is at at $t=0.01 \mathrm{sec} \&$ the torque is also controlled at near $t=0.01$ sec. 

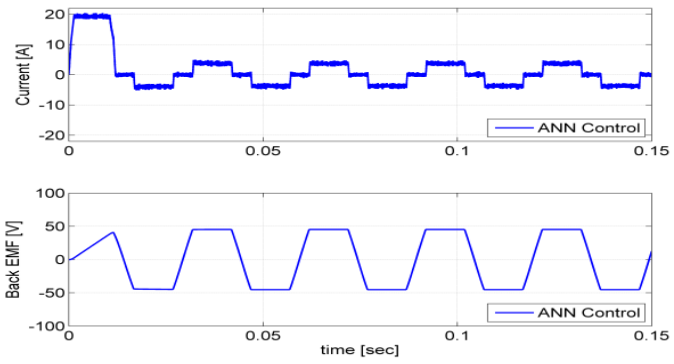

Fig.6 Figure shows Current and Back EMF by ANN controller from $t=0$ sec. After the time $t=0.01$ sec the current $\&$ EMF will follows the trapezoidal waveform

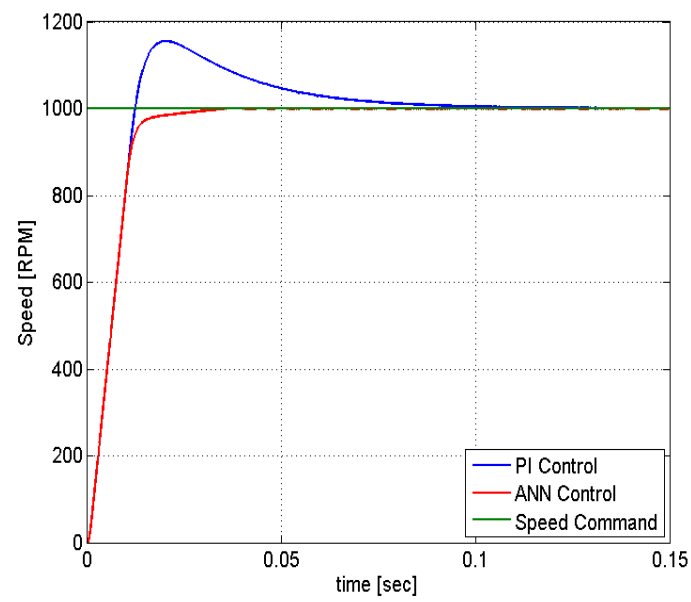

Fig.7 Figure shows the Speed response of BLDC for both controllers at $t=0$ sec. Here by comparing both the responses the speed is controlled at $0.07 \mathrm{sec}$ for PI controller and for

ANN controller the speed is controlled at 0.01 sec.
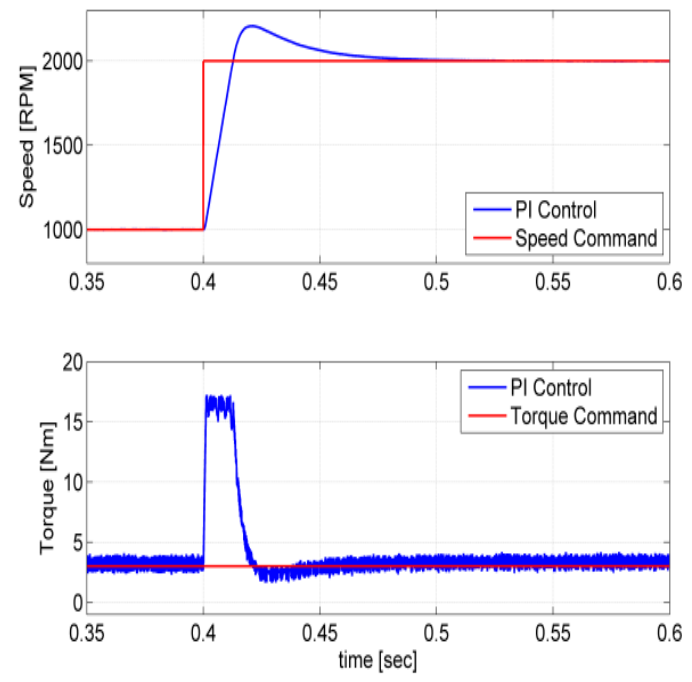

Fig.8. Figure shows the speed and torque response of PI controller at time $t=0.4 \mathrm{sec}$, here by $P I$ controller the speed is controlled at $\mathrm{t}=0.48 \mathrm{sec} \&$ the torque is controlled at $\mathrm{t}=\mathbf{0 . 4 3}$ sec.
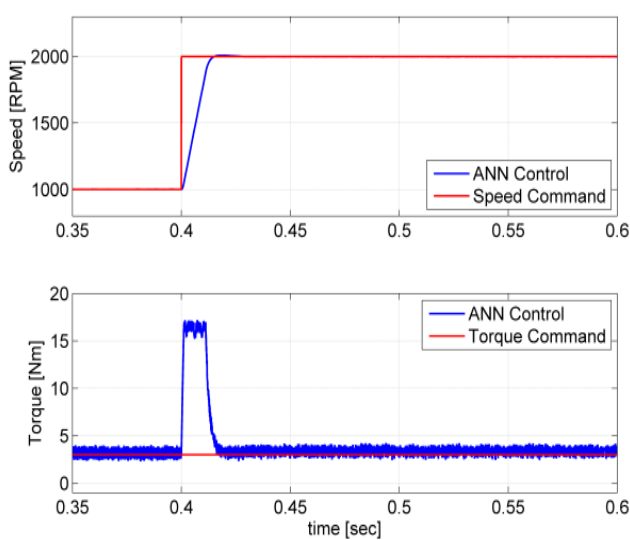

Fig.9 Figure shows the Speed and torque response of ANN controller at $\mathrm{t}=0.4 \mathrm{sec}$. Here by ANN controller the speed is controlled very quickly that is at at $\mathrm{t}=0.42 \mathrm{sec} \&$ the torque is controlled at near $\mathrm{t}=0.42 \mathrm{sec}$
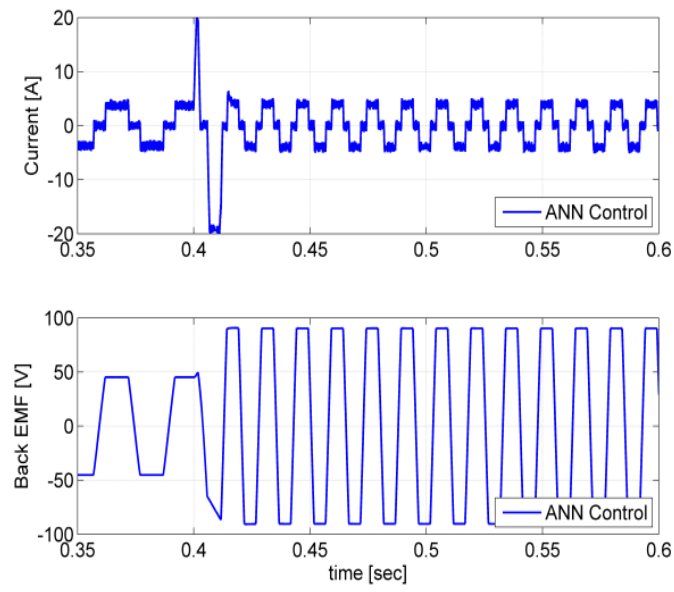

Fig.10 Figure shows Current and Back EMF by ANN controller at $\mathrm{t}=0.4 \mathrm{sec}$. After the time $\mathrm{t}=0.4 \mathrm{sec}$ the current $\&$ EMF will follows the trapezoidal waveform.

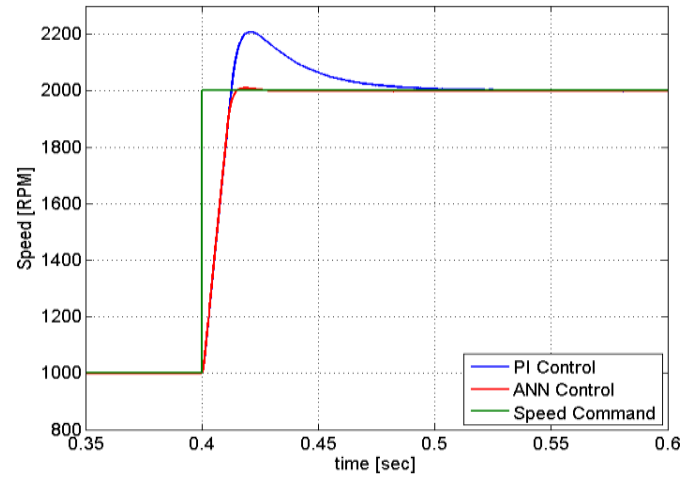

Fig.11. Figure shows the Speed response of BLDC for both controllers at $t=0.4 \mathrm{sec}$. Here by comparing both the responses the speed is controlled at 0.48 sec for PI controller and for ANN controller the speed is controlled at 0.42 sec. 

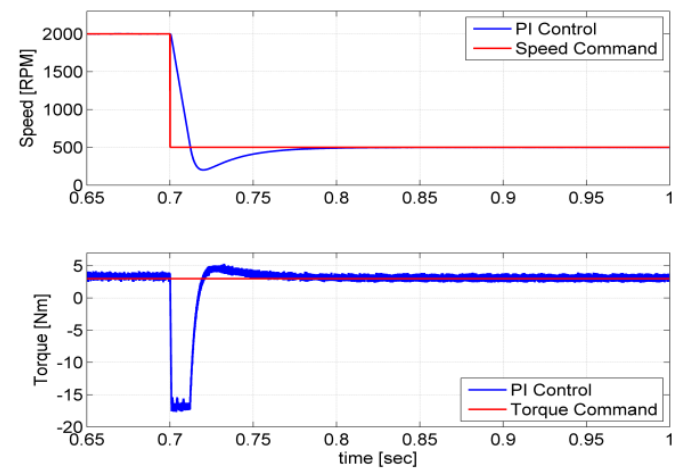

Fig.12 Figure shows the speed and torque response of PI controller at time $t=0.7 \mathrm{sec}$, here by $P I$ controller the speed is controlled at $\mathrm{t}=0.78 \mathrm{sec} \&$ the torque is controlled at $\mathrm{t}=\mathbf{0 . 7 6}$ sec.
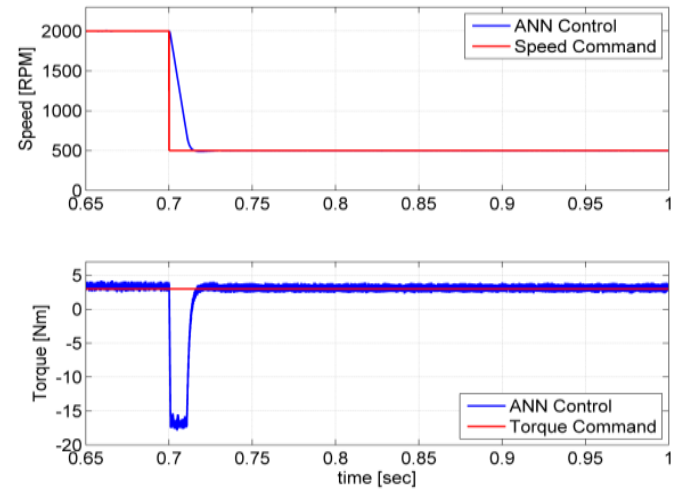

Fig.13Figure shows the Speed and torque response of ANN controller at $t=0.7 \mathrm{sec}$. Here by ANN controller the speed is controlled very quickly that is at at $t=0.72 \sec \&$ the torque is controlled at near $t=0.72 \mathrm{sec}$.
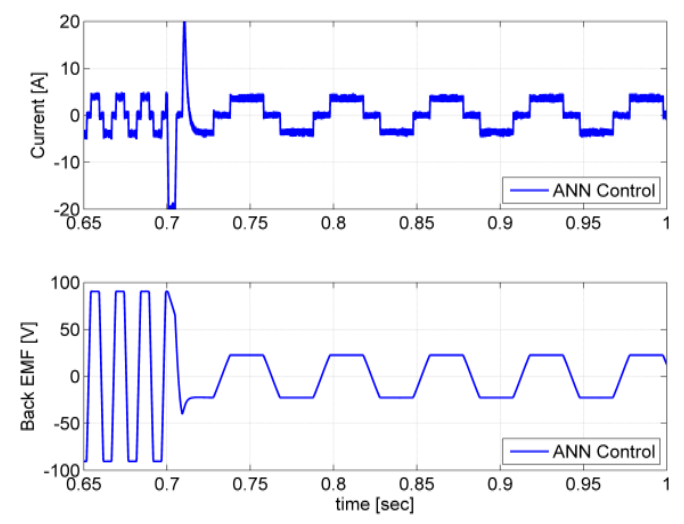

Fig.14 Figure shows Current and Back EMF by ANN controller at $t=0.7 \mathrm{sec}$. After the time $\mathrm{t}=0.7 \mathrm{sec}$ the current $\&$ EMF will follows the trapezoidal waveform.

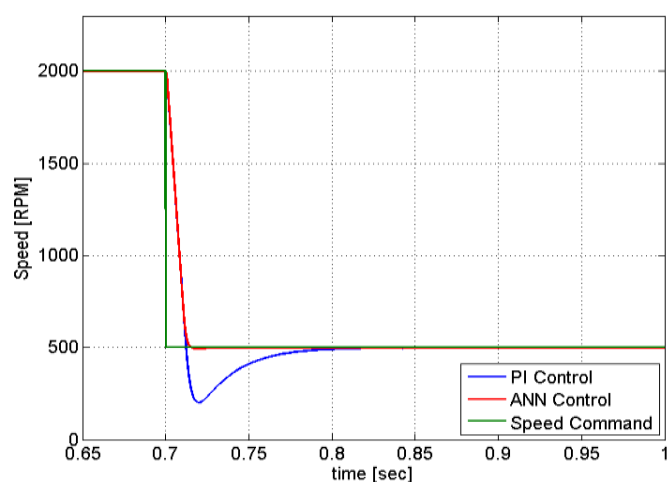

Fig.15 Figure shows the Speed response of BLDC for both controllers at $t=0.7 \mathrm{sec}$. Here by comparing both the responses the speed is controlled at 0.78 sec for PI controller and for ANN controller the speed is controlled at $0.72 \mathrm{sec}$.
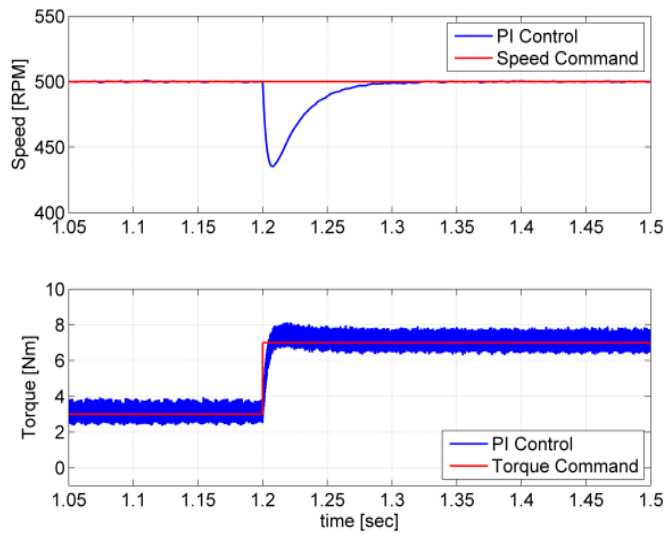

Fig.16 Figure shows the Speed and torque response of PI controller when the load increases from $3 \mathrm{Nm}$ to $7 \mathrm{Nm}$. when the load is suddenly increased the PI controller will controls the speed after the time $t=1.25 \mathrm{sec}$. and torque will follows the command signal.
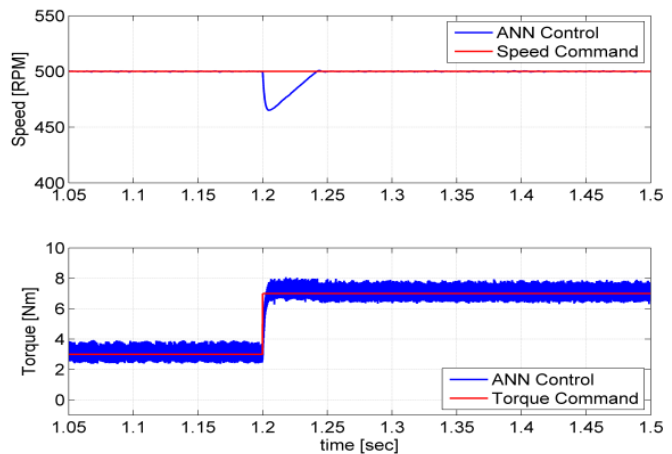

Fig.17 Speed and torque response of ANN controller when the load increases from $3 \mathrm{Nm}$ to $7 \mathrm{Nm}$. when the load is increased the ANN controller will controls the BLDC speed at time $t=1.2$ sec and output torque will perfectly follows the command signal. 

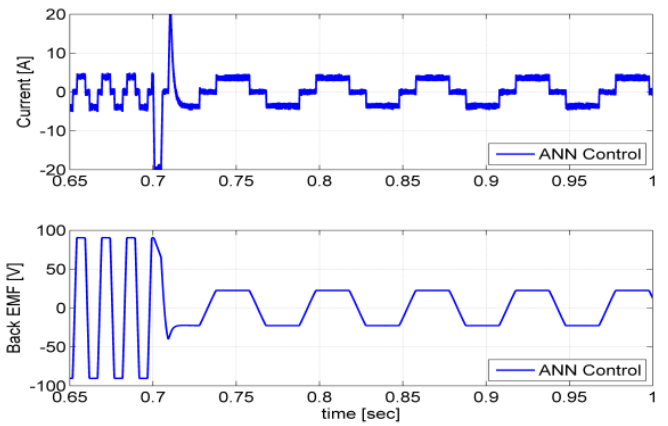

Fig.18 Figure shows the Current and Back EMF by ANN controller at $t=0.7 \mathrm{sec}$ when load is increased. Here when the load is increased from $3 \mathrm{Nm}$ to $7 \mathrm{Nm}$ the current and Back EMF will follows the trapezoidal waveform.

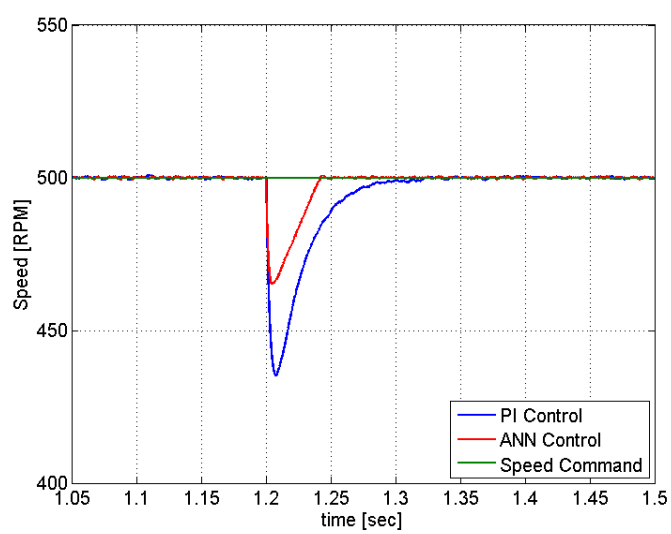

Fig. 19

Figure shows the Speed response of BLDC for both controllers when the load is increased from $3 \mathrm{Nm}$ to $7 \mathrm{Nm}$.

Here by comparing both the responses the speed is controlled after the time $1.25 \mathrm{sec}$ for PI controller and for ANN controller the speed is controlled before time $t=1.2 \mathrm{sec}$.

\section{CONCLUSION}

This paper presents the new approach for the controlling of BLDC motor. The MATLAB results for proposed controller and conventional PI controller are compared. It can be seen from the simulation results that the ANN controlling is giving better and accurate results than PI controlling. The simulation results for various operating conditions are illustrated and investigated. for all operating conditions ANN control will achieves the command signal quickly, this is the major advantage of using the ANN control in servo system applications. And also the proposed control will be stable and operates at desired values for any load changes within the ranges. The controller will tracks the reference speed variations and stabilizes the output during load variations.

\section{REFERENCES}

[1] J.R.Hendershot and T.J.E.Miller, Design of brushless Permanent-magnet Motors; Oxford, UK: Oxford Science, 1994.
[2] P.Pillay and R.Krishnan, Modeling, Simulation and Analysis of Permanent-magnet Motor Drives, part II: The brushless DC Motor Drive, IEEE Transactions on Industry applications, vol.25,no.2,march/April 1989.

[3] A.K.Wallace and R.Spee, The effects of motor parameters on the performance of brushless DC drive, IEEE Transactions on Power Electronics, vol.5, no.1, pp.2-8, January 1990.

[4] Astrom, K.J. and Wittenmark, B. (2000). Adaptive Control, 2nd ed., Englewood Cliff, NJ: Prentice Hall, pp.187-222. Varatharaju, V. M., Mathur.B.L., Udhyakumar.K., Speed control of PMBLDC motor using MATLAB/Simulink and effects of load and inertia changes, 2010 2nd International Conference on Mechanical and Electrical Technology(ICMET) 10-12Sept.2010,pp.543-548

[5] Ting-Yu Chang; Ching-Tsai Pan; Fang, E.; A Novel High Performance Variable Speed PM BLDC Motor Drive System; Power and Energy Engineering Conference; pp. 16, $2010 \quad$ Asia-Pacific [7] N.Norgaard, O.Ravn, N.K.Poulsen and L.K.Hansen, Neural networks for modeling and control of dynamic systems; 2nd edition, Springer-Verlag London Ltd.

[6] Vas,P.,Artificial-Intelligence-BasedElectrical Machines and Drives, Oxford University Press

[7] Artificial Neural Networks,Ajith Abraham Oklahoma State University, Stillwater, OK, USA

[8] Fausett,L.(1994) Fundamentals of Neural Networks,PrenticeHall,USA.

[9] J. C. Basilio and S. R. Matos, Design of PI and PID Controllers with Transient Performance Specification, IEEE Transactions on Education.

[10] A.ODwyer, Handbook of PI and PID Controller Tuning Rules, London, U.K:Imperial College Press, 2003.

\section{AUTHOR PROFILES}

Ms .Laxmi prasanna.CH received the B.TECH degree in Electrical and Electronics Engineering from Jaya institute of science and Technology, KAKATIYA UNIVERSITY, WARANGAL. Currently she is Pursuing M.TECH in power electronics at Siddhartha Institute of Engineering and Technology, Jawaharlal Nehru Technical University, Hyderabad.

Mr. Ramesh Palakeerthi received B Tech, M tech degree from JNTU. He has been submitted his $\mathrm{PhD}$ thesis in electrical engineering. Currently he is an associate professor and head of electrical \& electronics engineering department at Siddhartha Institute of Engineering and Technology, Hyderabad. He has published many technical papers in various international journals. $\mathrm{He}$ is a corporate member of the Institute of engineers, life member in Indian society of technical education and also member in association of international engineers, society of computer science and information technology. His area of research includes special machines, power and energy, soft computing and power electronics applications. 